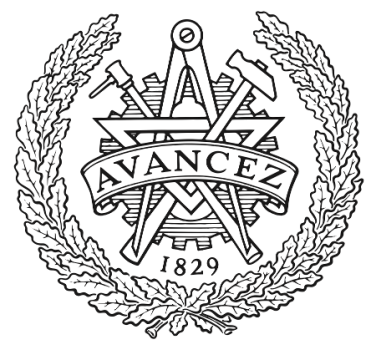

CHALMERS

UNIVERSITY OF TECHNOLOGY

\title{
Numerical and Experimental Aerodynamic Investigation of an S-Shaped Intermediate Compressor Duct with Bleed
}

Downloaded from: https://research.chalmers.se, 2023-04-26 10:04 UTC

Citation for the original published paper (version of record):

Siggeirsson, E., Andersson, N., Olander Burak, M. (2021). Numerical and Experimental Aerodynamic Investigation of an S-Shaped Intermediate Compressor

Duct with Bleed. Journal of Turbomachinery, 143(10). http://dx.doi.org/10.1115/1.4050670

N.B. When citing this work, cite the original published paper. 


\author{
Elias M. V. Siggeirsson ${ }^{1}$ \\ Division of Fluid Dynamics, \\ Chalmers University of Technology, \\ Gothenburg SE-41296, Sweden \\ e-mail: elias.siggeirsson@gmail.com \\ Niklas Andersson \\ Professor \\ Division of Fluid Dynamics, \\ Chalmers University of Technology, \\ Gothenburg SE-41296, Sweden \\ e-mail: niklas.andersson@chalmers.se

\section{Markus Burak Olander} \\ Department of 9600-TLab3, \\ GKN Aerospace Engine Systems Sweden, \\ Trollhättan SE-46181, Sweden \\ e-mail: markus.olander.burak@gknaerospace.
}

Numerical and Experimental Aerodynamic Investigation of an S-Shaped Intermediate Compressor Duct With Bleed

A series of computational fluid dynamics (CFD) simulations are performed to analyze the effects a rotor off-take bleed has on the performance of an intermediate compressor duct (ICD). To validate the CFD results, a comparison is made to measurements obtained from an experimental facility located at GKN Aerospace Engine Systems in Sweden. To achieve a deeper understanding of the flow physics, hybrid Reynolds-averaged NavierStokes/large eddy simulation (RANS/LES) simulations are performed for a single operating condition. The CFD simulations are capable of predicting the behavior when extracting large amount of air through the bleed pipe, where an improved prediction is obtained with the hybrid simulation. The performance of the ICD is severely compromised with increased amount of bleed as the flow delivered to the downstream component is highly disturbed. The disturbed flow is caused by the extraction of axial flow through the bleed pipe, increasing the incidence into the low-pressure compressor's outlet guide vanes (OGVs) resulting in unfavorable velocity profiles into the ICD. This behavior causes the flow to separate at the OGV blades, where the separation increases with increasing bleed. Furthermore, when including the full bleed system, significant circumferential distortions are observed, showing the necessity of the integrated design. [DOI: 10.1115/1.4050670]

Keyword: computational fluid dynamics (CFD)

\section{Introduction}

The demand for highly efficient aircraft engines has risen over the past decades and pushed engine manufacturers to seek for further improvements. This has led to the development of high-bypass-ratio turbofan engines with large fans and high-pressure ratio engine cores.

With the objective to make the engines shorter and lighter, the intermediate compressor duct (ICD) has become a subject of interest. The ICD is an S-shaped duct which connects the two compression stages, the upstream booster/low-pressure compressor (LPC) and the downstream high-pressure compressor (HPC). The relative location of the compression system in a modern turbofan engine is presented in Fig. 1. To get an efficient compression, the LPC tends to have large hub-to-tip ratio, whereas the HPC has lower radius to limit the tip leakage losses and reduce the weight of the rotor disk. To lead the flow through the radial offset, it is common to use an $\mathrm{S}$-shaped duct, where the radial offset between the LPC and the HPC is increasing with the evolution of increased bypass-ratio engines. The radial turning of the flow should be done in as short axial distance as possible to limit the length/weight of the engine. The axial distance is, however, limited by the risk of separation in the duct, due to the adverse pressure gradient present at the inner casing (hub). Furthermore, the ICD design should deliver reasonable inlet conditions to the HPC as highly disturbed flow has negative impact on the HPC's performance.

The LPC and the HPC have been optimized over the past decades. The performance of the ICD itself, on the other hand, has not been analyzed to the same extent, even though the "simple" geometry is actually exposed to challenging aerodynamics. Britchford et al.

\footnotetext{
${ }^{1}$ Corresponding author.

Contributed by the International Gas Turbine Institute (IGTI) of ASME for publication in the Journal of TURBOMACHINERY. Manuscript received December 5 , 2020; final manuscript received February 24, 2021; published online May 12, 2021. Tech. Editor: David G. Bogard.
}

$[1,2]$ analyzed the internal flow field of an annular S-shaped duct in detail, using experiments and computational fluid dynamics (CFD). These studies were performed to understand the flow physics of an S-shaped duct without any effects from integrated blades. Bailey et al. $[3,4]$ showed that with realistic inlet boundary conditions, the boundary layer is re-energized and the adverse pressure gradient at the inner casing becomes lower, reducing the risk of separation. More realistic boundary conditions, therefore, increased the possibility of a shorter duct, underlining the importance of an integrated design. Walker et al. [5] showed that by integrating the LPC's outlet guide vanes (OGVs) into the ICD, the system length could be reduced by $21 \%$. Additionally, insignificant difference in overall system losses was observed. Walker et al. [6] analyzed the effects when including a bleed pipe in the convex turning on the inner casing to extract the boundary layer. This was done to transfer a higher momentum fluid from the main flow towards the inner casing, decreasing the probability of separation.

Grimshaw et al. $[7,8]$ studied the effects on a compressor stage when extracting flow through a bleed pipe upstream of the rotor. The bleed pipe was integrated into the casing with a continuous outlet and a full bleed system with a single outlet. Extracting flow

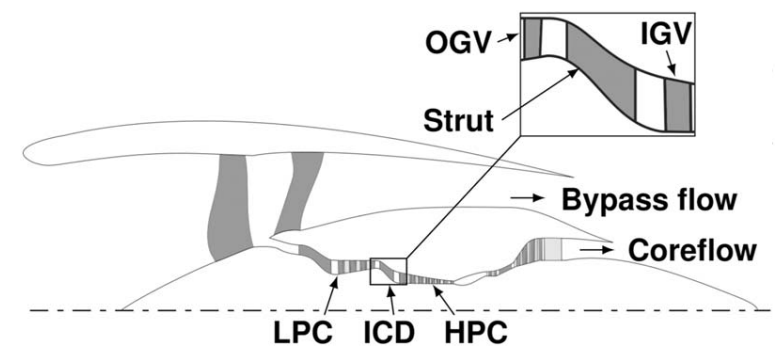

Fig. 1 A schematic of a turbofan engine 
through the bleed pipe had a positive impact on the stall margin and the full bleed system resulted in circumferential flow variations.

Siggeirsson et al. [9] studied the effects of an integrated bleed pipe in the casing, upstream of the OGV (rotor off-take). The geometry was simplified to limit the computational cost, where the rotor was replaced with a stationary blade row and the bleed pipe was a simple channel. The purpose of such integrated bleed configuration is not to extend the stability of the ICD but to improve the performance of the engine (cooling, pressurizing cavities, cabin air, particle extractions, etc.). It was expected that extensive amount of bleed would cause the flow in the ICD to separate at the hub, due to the flow diffusion towards the casing. However, no signs of separation were observed for two operating conditions $(10 \%$ and $30 \%$ of the inlet mass-flow was extracted). This was the motivation for using wall-functions when simulating the same configuration by Siggeirsson et al. [10], where the ANSYS hybrid Reynolds-averaged NavierStokes/large eddy simulation (RANS/LES) turbulence model, stress-blended eddy simulation (SBES), and the RANS turbulence model, $k-\omega$ shear stress transport (SST) were used. The SBES model was compared to the $k-\omega$ SST model and experiments. The wall-function simulations resulted in better agreement between the CFD and the experiments, compared to a wall-resolved RANS simulation, which over-predicted the flow separation at the OGV blades. Furthermore, the SBES model improved the CFD predictions compared to the wall-function RANS simulations. Even though the simulations using wall-functions gave promising results, the assumption of no major separation had to be made, limiting the exploration of different operating conditions. The same configuration is the subject of the current study but with an extension to the bleed system geometry, where the full bleed system is included. Additionally, to take full advantage of the hybrid method, wall-resolved simulations are performed.

Most modern industrial CFD analyses are performed by applying RANS models, as they give reasonable estimations of averaged quantities with relatively low computational cost. However, these models need to be replaced with more advanced techniques to better capture unsteady flow structures and dynamics caused by the complicated interaction between the curvature effects and the adverse pressure gradients $[1,10]$. Therefore, to take full advantage of the integrated design, a move from the standard RANS-based simulations to more detailed numerical simulation techniques such as LES is made. However, even though computational power is increasing, pure LES will not become a practical option for industrial use in high-Reynolds number turbomachinery applications with complex geometries in the near future [11]. Therefore, a hybrid RANS/LES method is considered as it combines the advantages of LES in resolving separated flows and the unsteady flow features of the main flow and RANS models capabilities in simulating attached boundary layers and mildly separated flows.

To analyze the integrated ICD and the effect the bleed system has on the flow field, a full annular, experimental test rig has been built at GKN Aerospace Engine Systems (GKNAES) in Trollhättan, Sweden. The test section of the rig is presented schematically in Fig. 2, where the non-dimensional duct characteristics are given in Table 1 . Those characteristics identify how prone to separation the duct is, where an increase in $\Delta R / L, A_{\text {out }} / A_{\text {in }}$, and $\dot{m}_{\text {bleed }}$ has a similar effect on the duct's performance (often referred to as a higher loaded duct). Higher loading will increase the magnitude of the deceleration area at the hub, resulting in higher risk of separation. The duct presented here is moderately to highly loaded, representing a realistic state-of-the-art ICD from a modern engine design.

This paper is a part of a continuing investigation at Chalmers and GKNAES. In the present study, the internal flow field of an S-shaped ICD, including the full bleed system, is analyzed. RANS simulations are performed for four operating conditions, where different amounts of bleed are extracted $(0 \%, 10 \%, 30 \%$, and $40 \%$ of the inlet mass-flow). Furthermore, the $10 \%$ operating condition is simulated using the SBES turbulence model and compared to the measurements and the RANS simulations. The aim of the work is to get a deeper understanding of the flow behavior in an

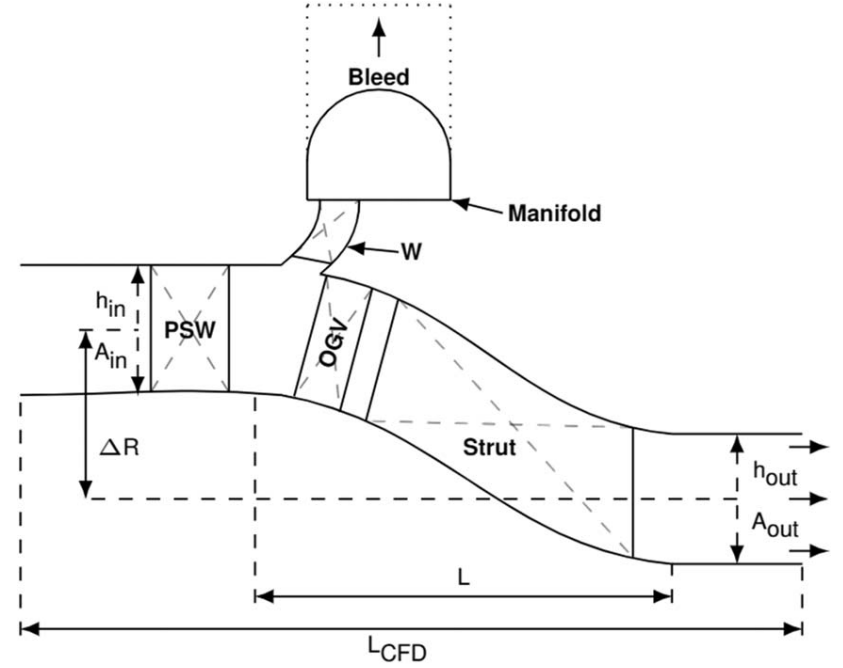

Fig. 2 Schematic of the integrated ICD

Table 1 Non-dimensional duct characteristics

\begin{tabular}{ll}
\hline \hline$\Delta R / L$ & 0.42 \\
$A_{\text {out }} / A_{\text {in }}$ & 0.67 \\
$h_{\text {in }} / L$ & 0.21 \\
\hline \hline
\end{tabular}

ICD to improve future design methodologies and guidelines, resulting in improved aircraft engines.

\section{Experimental Setup}

The experimental rig, which is represented by Fig. 2 (showing the test section only), is located at GKNAES, Trollhättan, Sweden. It has been included in previous studies $[9,10]$ but the experimental description is included here for completeness. The rig is connected to the compression system through a stagnation chamber, where the contraction ratio to the first part of the annular channel is approximately 5:1. The geometry of the rig is similar to the ICD from a real aircraft engine component. However, a pre-swirler (PSW) is located in the first section of the channel. The PSW is there to mimic a rear stage LPC rotor, turning the bulk flow in a similar direction as the rotor would do. The inclusion of a stationary PSW instead of a rotor stage simplifies the setup of the rig and saves computational power when running CFD simulations. However, making this simplification limits the transient behavior of the flow. For example, the PSW wakes will be stationary, and there is no tip-clearance flow generated between the rotor and the casing and the bleed will not impact the radial loading distribution of the upstream rotor. The test section consists of an ICD with integrated OGVs, struts, and a rotor of-take bleed system. The OGVs are designed to minimize the upstream potential field of the strut and to deliver axial flow into the ICD. The strut is a non-lift bladeprofile located in the duct to increase the mechanical strength and stability and to allow for necessary connections to the engine core (such as oil-piping and electricity). The bleed pipe is used to extract flow from the main flow-path, where the bleed air is used for different applications, such as cabin air and ice protection, and to uncouple the mass-flow through the LPC and the HPC for a better off-design control.

Figure 2 presents the full bleed system, where the bleed pipe connects the main flow bath to a 360 deg bleed manifold, surrounding the test rig. The bleed pipe is divided into 18 slots, where the slots are separated with struts, placed there to add mechanical strength to the test rig (marked W in Fig. 2). On the bleed manifold, there are 


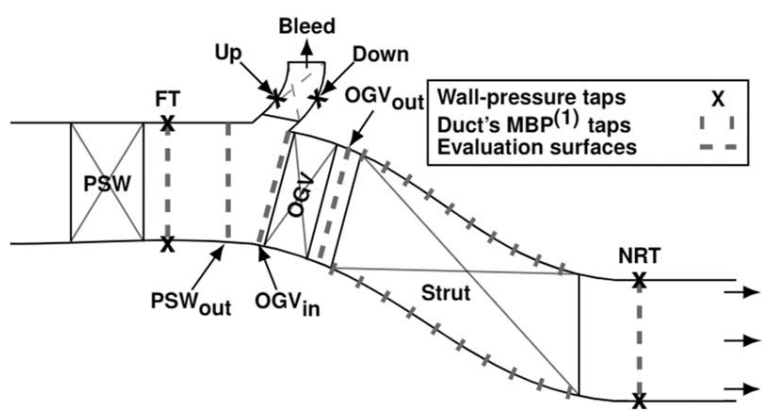

Fig. 3 Location of experimental measurements. The bleed pipe manifold is excluded from the figure. MBP represents the axial end-wall distribution of wall pressure taps in-between the two struts. The figure is not to scale.

four exit pipes, marked with the dotted line in Fig. 2, where the bleed flow is extracted from the facility. The outlet pipes are evenly distributed with $90 \mathrm{deg}$ between the outlet center.

In a modern turbofan engine, the number of OGVs are usually an order of magnitude greater than the number of struts. To make the CFD simulations simpler, the experimental rig was designed with nine struts, resulting in 81 OGVs. Furthermore, the number of PSW is 45 , resulting in a common denominator of 9 . The common denominator could cause problems if the configuration would have rotating components but as it is purely stationary this is assumed to have insignificant effects. To be able to achieve a specific Reynolds number, the outlet of the ICD is connected to a ejector system where the pressure is lowered below atmospheric pressure. The operating condition of the rig is controlled by an inlet valve, an outlet valve, and the outlet ejector settings.

A five-hole probe is used for the mapping of the inlet and outlet fields at two different axial positions, where each axial position includes tangential and radial traversing of the probe (marked with a dashed line in Fig. 3). The probe position is set by controllable servo motors. The traverse sections are presented in Fig. 3 where representative surfaces for the front traverse (FT) and the near rear traverse (NRT) are shown. Furthermore, the nondimensional axial position of each surface is presented in Table 2 . At the FT surface, the pressure probes extract data at three different radial spans $(10 \%, 50 \%$, and $90 \%)$ whereas at the NRT and FT surfaces, the pressures are extracted at five different radial spans $(10 \%$, $20 \%, 30 \%, 50 \%$, and $94 \%$ ). At all radial spans, the traverses cover a full strut's tangential sector, or $40 \mathrm{deg}$, with 6300 nodes at the FT surface and 3100 nodes at the NRT surface. The five-hole probe pressures are measured by a pressure scanner with a range of 35 $\mathrm{kPa}$ and specified uncertainty of $\pm 0.05 \%$. Summing up the measurement uncertainty for the reference pressure and the measured pressure, an uncertainty of $0.095 \%$ is obtained.

Additionally, there are static pressure taps mounted in the walls at four different axial positions, presented in Table 2 and marked with "x" in Fig. 3. In Table 2, the resolution of the pressure tap distribution is shown, where the pressure taps at the FT location are four and distributed over $360 \mathrm{deg}$ and at the NRT location there are five pressure taps distributed over $40 \mathrm{deg}$. In the bleed pipe, at the upstream and downstream locations, there are four pressure taps, distributed over $60 \mathrm{deg}$. Furthermore, there are ten static pressure

Table 2 Non-dimensional axial location of traverse planes and pressure taps

\begin{tabular}{lcccc}
\hline \hline & FT & Up & Down & NRT \\
\hline$x / L_{\text {CFD }}$ & 0.2 & 0.32 & 0.35 & 0.64 \\
Res. & $4 / 360 \mathrm{deg}$ & $4 / 60 \mathrm{deg}$ & $4 / 60 \mathrm{deg}$ & $5 / 40 \mathrm{deg}$ \\
\hline
\end{tabular}

Note: $L_{\mathrm{CFD}}=0$ in Fig. 2 is the reference point. taps mounted in the duct's hub and casing, in the strut's mid blade passage (MBP), marked with a dotted line in Fig. 3. The pressure taps extend from the strut's leading to trailing edges.

For each operating condition (measurements available for $10 \%$, $30 \%$, and $40 \%$ ), the wall pressures were measured during several different runs, creating a small dataset. This information is used to estimate the experimental uncertainty, where a single standard deviation is presented as the error bars in the results. This uncertainty is significantly larger compared to the equipment uncertainty and is therefore only considered in the comparisons.

\section{Numerical Method}

The commercial CFD solver ANSYS CFX (release 19.1) is used where two turbulence modeling approaches are considered. The hybrid, scale-resolving model, SBES, is used for a single operating condition (10\% bleed) as it has proven to be successful in protecting the boundary layer, even on grids with fine stream-wise cell sizes [12], and showed good results in previous studies on a similar configuration [10]. The $k-\omega$ SST two-equation turbulence model, from now on referred to as SST, is used in the RANS regions whereas in the LES regions, the sub-grid scales (SGS) are modeled using the wall adapting local Eddy-viscosity (WALE) algebraic model [13]. The idea behind the SBES model is to explicitly change between LES and RANS, using a shielding function, $f_{s}$. When both the RANS and SGS models are eddy-viscosity-based models, the SBES model eddy-viscosity is defined as

$$
\nu_{t}^{\mathrm{SBES}}=f_{s} \cdot \nu_{t}^{\mathrm{RANS}}+\left(1-f_{s}\right) \cdot \nu_{t}^{\mathrm{LES}}
$$

where $f_{s}$ is the previously mentioned shielding function, designed to protect the boundary layer from being solved in LES mode. This function is unpublished and proprietary to ANSYS.

Additionally, steady RANS simulations are performed for four operating conditions $(0 \%, 10 \%, 30 \%$, and $40 \%$ bleed). In the RANS simulations, the turbulence is modeled using the SST model. Furthermore, all simulations resolve the boundary layers $\left(y^{+}<1\right)$.

\section{Computational Setup}

To lower the computational resources required for the CFD simulations, the size of the computational domain is limited as much as possible. As described in Sec. 2, the number of blades have a common denominator of 9, with 45 PSWs, 18 bleed slots, 81 OGVs, and nine struts. However, there are only four bleed manifold outlets, meaning that to get the same tangential sector for all modules, the full $360 \mathrm{deg}$ has to be simulated. To simplify the problem, the assumption of one bleed manifold outlet per $80 \mathrm{deg}$ tangential sector is made, where the outlet cross-sectional area is scaled accordingly. Therefore, two struts ( $80 \mathrm{deg}), 10 \mathrm{PSWs}$, four bleed pipe slots, and $18 \mathrm{OGVs}$ are needed.

In Figs. 4-6, the computational domain is presented. Figure 4 shows a top view of the rig, where the bleed system and the casing have been removed for a better view of the blades. The

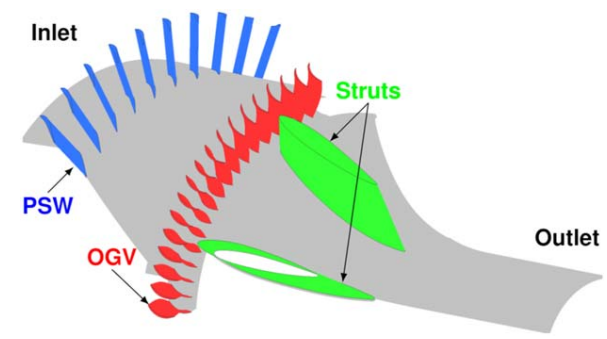

Fig. 4 Computational domain. Top view of blades where the casing and the bleed system have been removed for clarity 


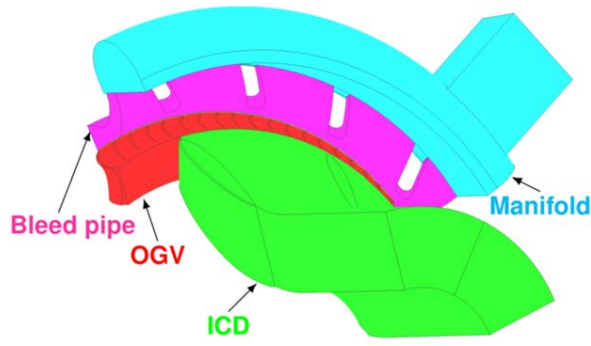

Fig. 5 Rear view of the computational domain

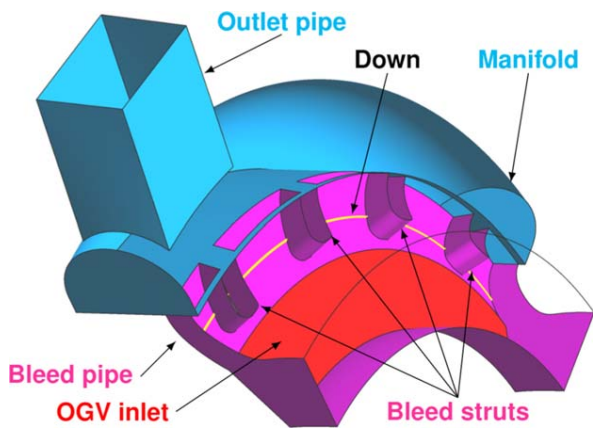

Fig. 6 Detailed view of the bleed system

full bleed system, along with the OGV and the ICD modules, is presented in Fig. 5. A detailed view of the bleed system is shown in Fig. 6, where the bleed module casing and the upstream half of the manifold have been removed to better visualize the bleed struts and the system in general. Additionally, the location of the downstream pressure taps, presented in Fig. 3, is shown as a continuous line. There the geometry of the bleed pipe struts is visible and the single bleed manifold outlet pipe. Between the five modules, the PSW, bleed pipe, bleed manifold, OGV, and the ICD, a frozen rotor interface is specified to make sure that all transient flow dynamics and interaction effects are transported between different modules. The inlet of the domain is specified with a total pressure, total temperature, and velocity direction, whereas at the bleed pipe and the main flow-path outlets, pressure is specified. The physical time-step for the transient simulation is set to $10^{-5}$ with eight inner iterations for each time-step using second-order backward Euler time discretization. Furthermore, two through-flows $\left(L_{\mathrm{CFD}}\right)$ are needed to reach statistically steady-state and three through-flows are used for the time-averaging procedure.

Grid convergence study was performed for the RANS simulations with three different meshes (30M, 60M, and 80M). Global (mass-flow, blade forces, and bleed ratio) and local (radial profiles and wall pressure) quantities were monitored. The difference in total pressure loss for the two finer grids was within $0.1 \%$, therefore the $60 \mathrm{M}$ grid was used. Due to the nature of the SBES model, a conventional grid convergence study is difficult to perform, as smaller cells result in smaller resolved scales. Two meshes were studied $(20 \mathrm{M}$ with wall-functions and $60 \mathrm{M}$ with $y^{+}<1$ ), with negligible difference when considering radially averaged profiles and wall pressures. There were, however, large differences observed in the magnitude of resolved scales as they are directly coupled to the cell sizes. A high-resolution advection scheme is used for the RANS simulations, whereas a bounded central differencing (BCD) scheme is specified for the hybrid simulations. The highresolution scheme is a second-order upwind scheme that falls back to a first-order upwind scheme in case of stability problems. The BCD scheme switches between the central differencing scheme and second- or first-order accurate upwind discretization. The central differencing scheme is ideal for scale-resolving
Table 3 Mesh statistics

\begin{tabular}{lccccc}
\hline \hline PSW & Bleed & Manifold & OGV & ICD & Total \\
\hline $16.9 \mathrm{M}$ & $6.6 \mathrm{M}$ & $2.6 \mathrm{M}$ & $17.7 \mathrm{M}$ & $15.8 \mathrm{M}$ & $59.6 \mathrm{M}$ \\
\hline \hline
\end{tabular}

simulations but can lead to nonphysical oscillations, therefore the BCD scheme includes an upwind component for numerical stability [14].

The computational grid of the main flow-path is generated with the in-house tool G3dmesh, whereas the bleed pipe and the bleed manifold are generated using the commercial software ANSYS ICEM. The boundary layers in the main flow-path are resolved, with the aim to keep the averaged $y^{+}$value in the range of 1-2 [15] with 10-15 cells in the boundary layer. However, the bleed manifold is modeled using wall-functions. This is done since the main objective of the bleed manifold in the simulations is to transfer flow through sparse outlet pipes. The total number of cells for each module is presented in Table 3, where the mesh resolution is based on previous studies $[9,10]$.

\section{Normalization}

To compare the different methods, the experimental data and the CFD results are normalized. The radial profiles extracted at a specific evaluation surface are represented in terms of total pressure coefficient, Eq. (3), where the reference values are the mass-flow averaged total and static pressures over the whole surface, Eq. (2).

$$
\begin{gathered}
\tilde{P}=\frac{1}{\dot{m}} \int P d \dot{m}, \quad \tilde{p}=\frac{1}{\dot{m}} \int p d \dot{m} \\
C_{\mathrm{P}}^{\mathrm{r}}=\frac{\tilde{P}_{\text {sector }}-\tilde{P}_{\text {surface }}}{\tilde{P}_{\text {surface }}-\tilde{p}_{\text {surface }}}
\end{gathered}
$$

Contours of total pressure are compared at different evaluation surfaces in terms of the pressure coefficient

$$
C_{\mathrm{P}}^{\mathrm{c}}=\frac{P-\tilde{P}_{\text {surface }}}{\tilde{P}_{\text {surface }}-\tilde{p}_{\text {surface }}}
$$

The measured wall pressures from the pressure taps are normalized with the inlet total pressure, since the dynamic pressure signal had too much noise to provide a good normalization. The reference pressures for the CFD simulations are adjusted so that the intersection point of the duct's hub and casing wall pressures match the intersection point from the experimental data (Fig. 7). Those reference values are used to normalize the pressure in relevant CFD simulations. The wall pressures are compared at different axial locations where the static pressure is normalized with the reference total pressure.

$$
p_{\text {norm }}=\frac{p}{P_{\text {ref }}}
$$

Furthermore, the axial velocity is normalized with the area averaged velocity

$$
U_{\text {ave }}=\frac{\hat{U}_{\text {sector }}}{\hat{U}_{\text {surface }}}, \quad \hat{U}=\frac{1}{A} \int U d A
$$

\section{Results}

In this section, the CFD results are validated with the experimental data at locations presented in Fig. 3, for $10 \%, 30 \%$, and $40 \%$ bleed. The $0 \%$ bleed case is presented for comparison. Furthermore, the effects from extracting different amount of bleed through the bleed pipe are analyzed. The SST model is used to simulate all 


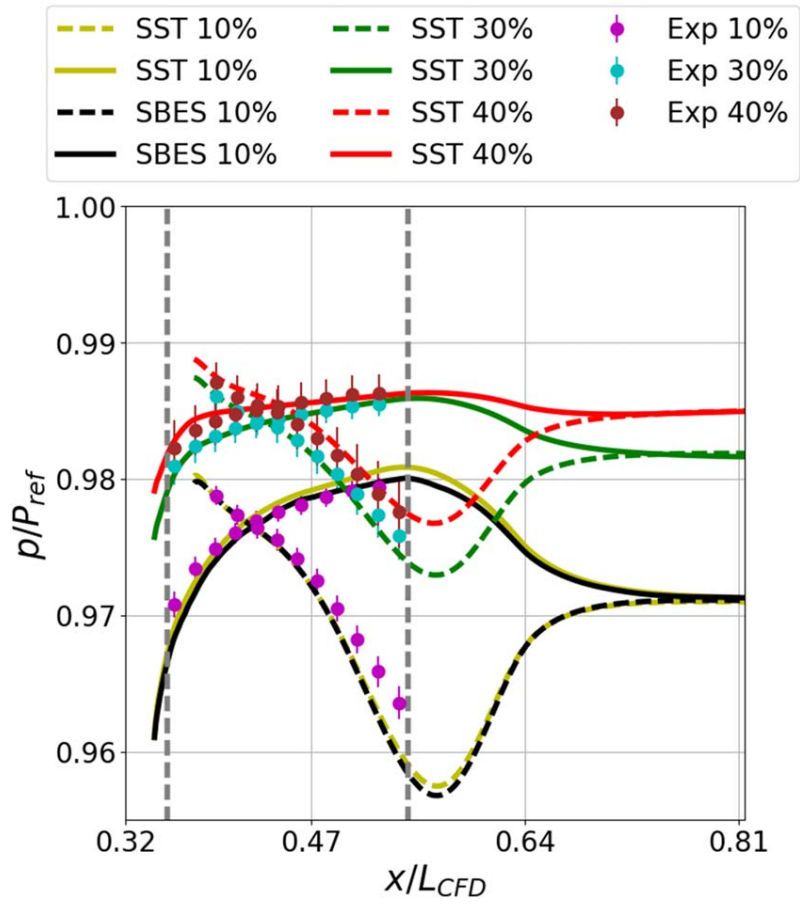

Fig. 7 Wall pressure in the ICD MBP. Dashed line, casing; solid line, hub

operating conditions, whereas the SBES model is used to simulate the $10 \%$ bleed case.

6.1 Validation. To build confidence in the CFD predictions, the simulations are compared to experimental data for three different operating conditions. The comparison is made in terms of wall pressures at several different axial locations in the MBP of the struts and radial total pressure profiles up- and downstream of the ICD.

The wall pressure in the MBP of the ICD is presented in Fig. 7, for the $10 \%, 30 \%$, and $40 \%$ operating conditions. The dashed vertical lines represent the axial location of the leading and trailing edges of the struts. Overall, the CFD simulations are capable of predicting the measured pressure, where some deviations are observed for the $10 \%$ bleed case at the casing, both the SBES and the SST models.

In Fig. 8, the radial profiles of the total pressure coefficient (Eq. (3)) are presented, both at the FT and NRT evaluation surfaces. Figure 8(a) shows the radial profile for the FT evaluation surface which is located downstream of the PSW. At the FT evaluation surface, information about the inlet conditions for the integrated

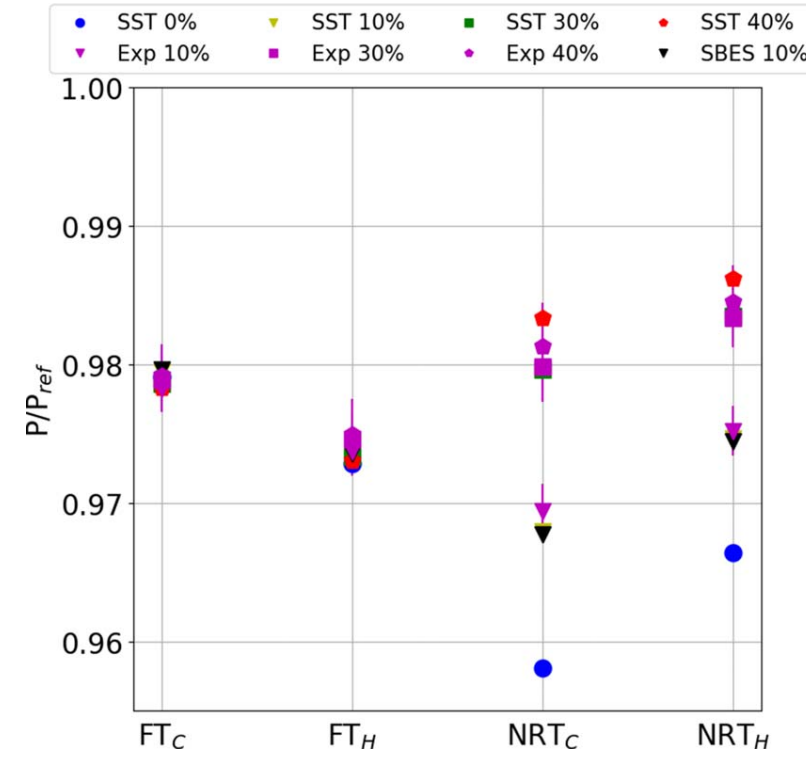

Fig. 9 Wall pressure at different axial locations

ICD are extracted. It is important that all CFD results are within the measured values. Furthermore, since the FT evaluation surface is located relatively far upstream from the bleed pipe, the different bleed fractions should have insignificant effects on the total pressure profile. This was observed in the measurements and therefore, only a single experimental profile is presented in the figure. All CFD simulations are capable of reproducing the measured profile, where the SBES results show signs of larger corner vortices near the casing.

The same profiles are compared in Fig. 8(b) at the NRT evaluation surface, downstream of the ICD. There, measurements from two operating conditions are presented $(10 \%$ and $40 \%)$. Tangential traverses were not obtained for the $30 \%$ bleed fraction. Overall, the SST results are capable of capturing the measured profiles, when the uncertainty is taken into consideration. There is, however, a clear improvement when considering the $10 \%$ SBES results, especially near the hub. From the two measurements, the effects from the different bleed fraction on the total pressure are correctly predicted by the CFD.

Figure 9 shows a comparison between wall pressure for the CFD simulations and the experiments at two different axial locations (FT and NRT in Table 2). All operating conditions are included in the figure, where the $0 \%$ is there for comparison reasons. All CFD simulations are in a good agreement with the measurements. The difference in terms of wall pressure between the SBES and SST models at $10 \%$ bleed was $\Delta p / P_{\text {ref }}= \pm 0.03 \%$. The effects from (a)

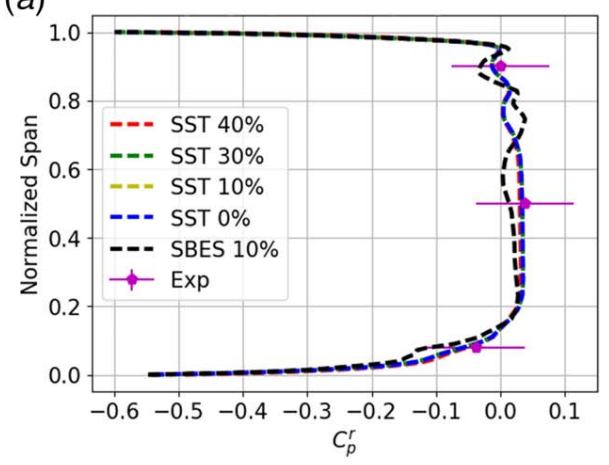

(b)

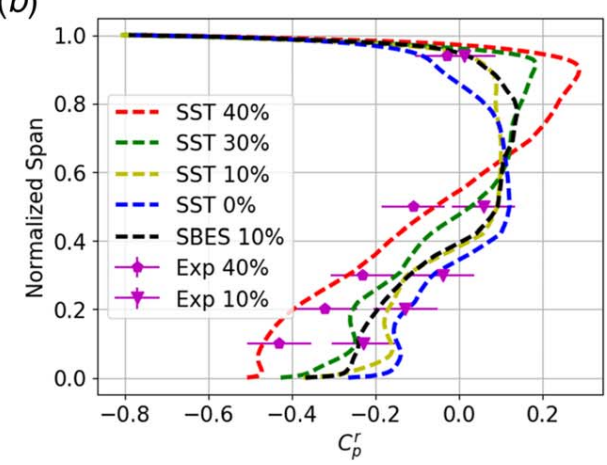

Fig. 8 Radial profiles of total pressure coefficients: (a) FT evaluation surface and (b) NRT evaluation surface 
the bleed are evident, where the wall pressure downstream of the ICD increases with increased bleed. This behavior is mainly caused by the reduced mass-flow entering the ICD flow-path, lowering the velocity.

Comparing the CFD simulations to the measurements, it is obvious that there are localized differences. However, the main trends when extracting flow from the main flow-path through the bleed pipe are correctly captured by the simulations. Therefore, the CFD results are further analyzed and the effects from different operating conditions studied.

6.2 Bleed Effect. The experimental data are limited as it can be difficult to fit the measurement equipment at some locations. Furthermore, for this experimental campaign, the traverses do not have sufficient resolution to provide detailed contours of the flow. Therefore, the CFD simulations are compared in terms of contours and radial profiles of variables not obtained in the measurements.

In Fig. 10, the normalized axial velocity profiles are shown at the four evaluation surfaces (Fig. 3). As expected, the effects from the different bleed ratios are negligible. At the $O G V_{\text {in }}$ evaluation surface, the effect due to the extracted flow is seen. To account for the mass-flow extracted through the bleed pipe, the flow near the hub is accelerated and diffuses towards the casing. The axial acceleration is further magnified due to the geometry of the ICD. Separation is present at the casing, due to the sharp corner in the bleed pipe geometry. Furthermore, there are differences near the hub between the SBES and the SST results for the $10 \%$ bleed fraction. For the $\mathrm{OGV}_{\text {out }}$ evaluation surface, the bulk axial flow is of similar shape, where significant difference is observed in the boundary layers. For the active bleed cases, the flow is accelerated relatively more near the casing due to the high momentum fluid transported from the main flow. Near the hub, the flow is decelerated with increased bleed. Downstream of the ICD, at the NRT evaluation surface, the shape of the axial velocity is significantly dependent on the operating condition. Near the hub, the deceleration is more extreme with increased amount of bleed. This behavior can result in of separation, if the attached boundary layer would not be able to counteract the adverse pressure gradient. However, the boundary layer is re-energized due to the strong mixing of the OGV wakes, increasing the stability margin of the ICD. Near the casing, the opposite behavior is observed, where the flow is accelerated due to the convex turning of the casing wall. Considering the SBES results, there is a significant difference compared to the SST results near the hub. Similar behavior was observed previously in Fig. 8(b) where the SBES model gave a better agreement with experiments. It should be noted that this is the normalized velocity, meaning that the absolute velocity for the $0 \%$ operating condition is much higher compared to the $40 \%$ one.

For the same evaluation surfaces, the swirl is presented in Fig. 11. As before, there are minor differences observed at the FT evaluation surface, where the SBES model deviates from the SST results. At the $\mathrm{OGV}_{\text {in }}$ location, the swirl increases with increased bleed. This is caused by the higher amount of axial flow extracted through the bleed pipe, while the tangential velocity component is relatively unaffected. This puts stricter requirements on the OGV design as the incidence can take drastic changes. Furthermore, the radial velocity is increased, pushing the flow away from the hub. Downstream of the $\mathrm{OGV}$, at the $\mathrm{OGV}_{\text {out }}$ evaluation surface, the $0 \%$ bleed case delivers a relatively uniform swirl profile, around 2-3 deg for the $40 \%$ case. However, when increasing the bleed, the swirl profile becomes more nonuniform, where the swirl differs by more than
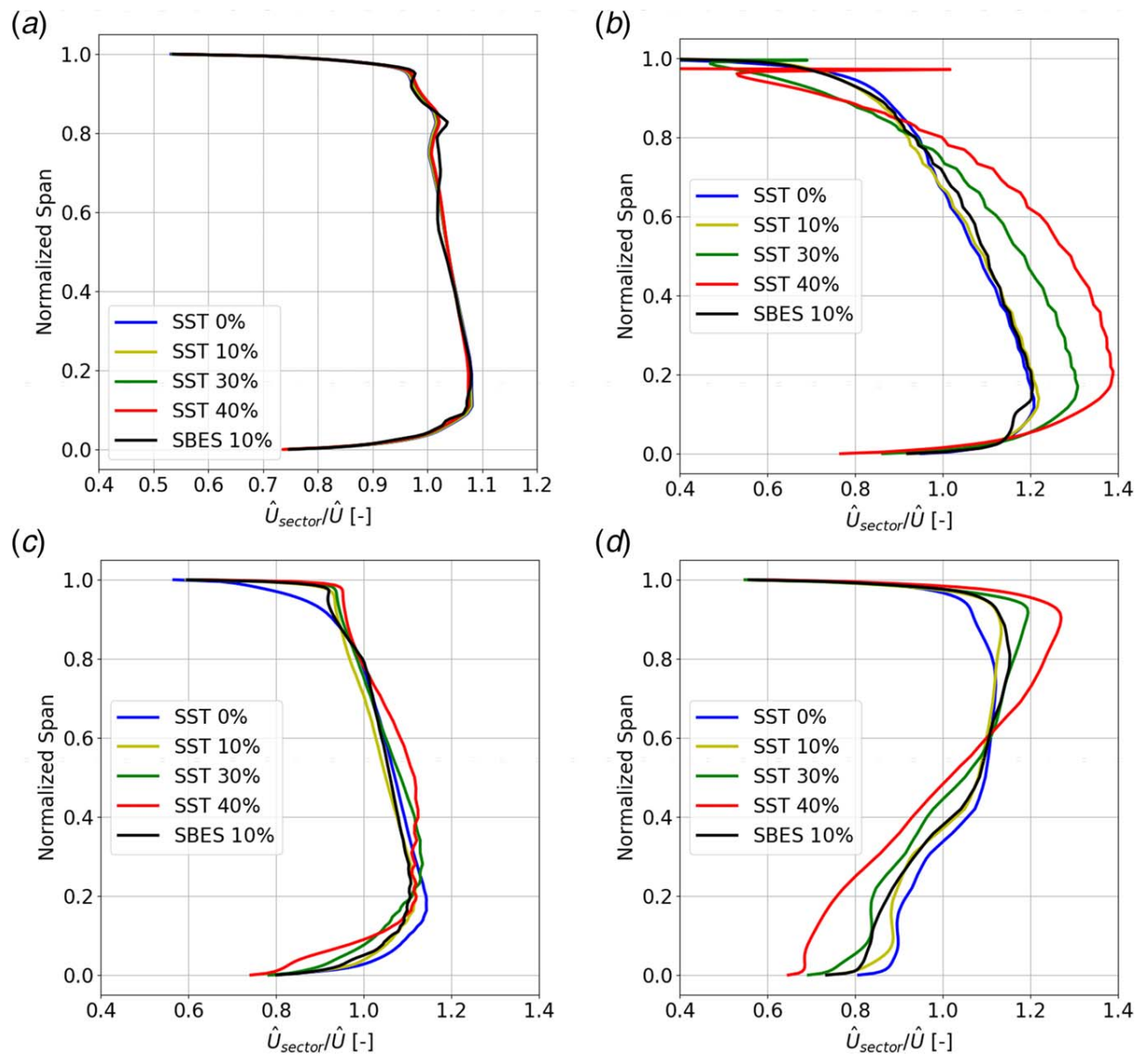

Fig. 10 Normalized velocity profiles: (a) FT evaluation surface, (b) $O G V_{\text {in }}$ evaluation surface, (c) OGV $_{\text {out }}$ evaluation surface, and (d) NRT evaluation surface 
(a)

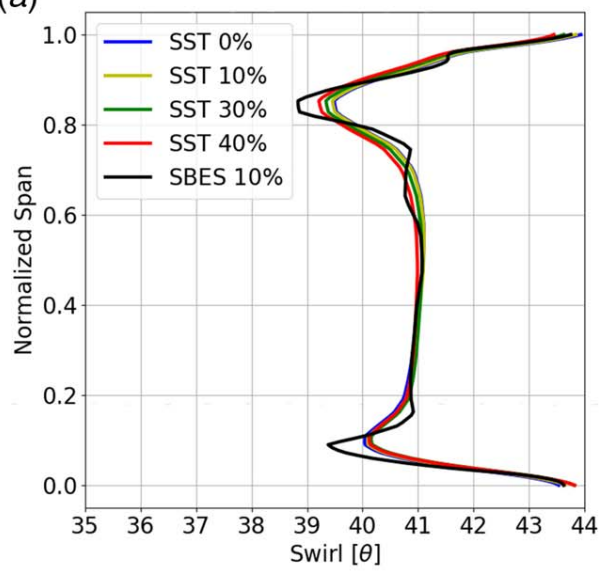

(c)

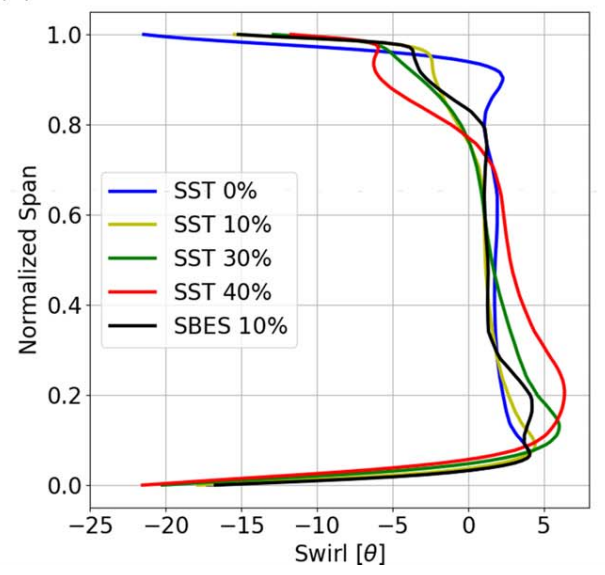

(b)

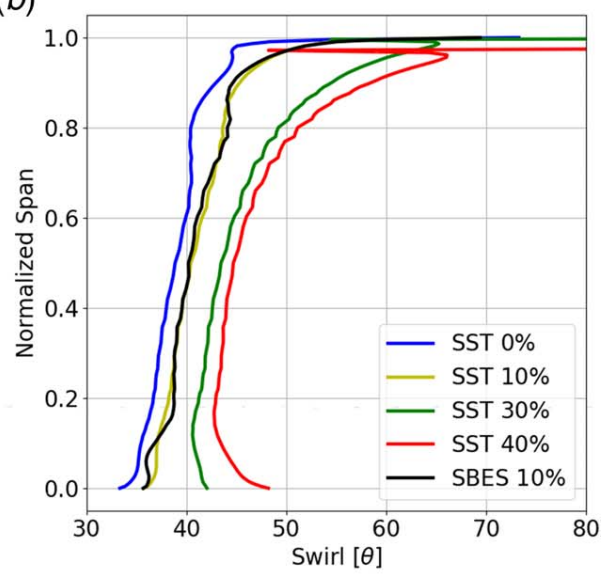

(d)

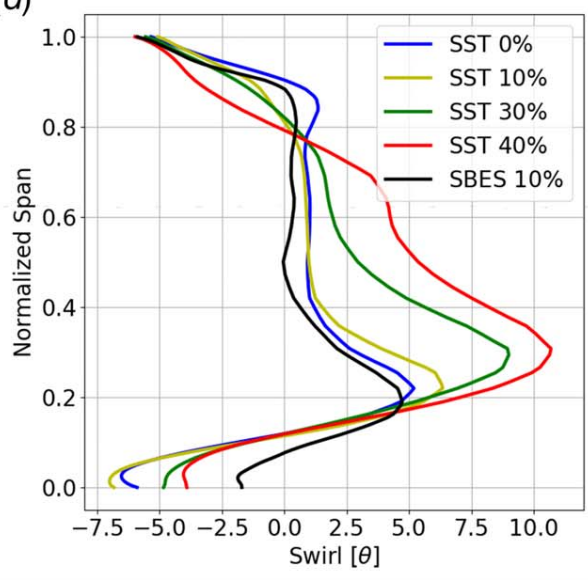

(c) OGV out evaluation surface, and (d) NRT evaluation surface

$10 \mathrm{deg}$ in the main flow-path. This behavior has a significant effect on the downstream strut, which is a zero lift wing profile, designed for relatively low incidence with low variations in the radial direction. At the NRT surface (Fig. $11(d)$ ), the $0 \%$ and $10 \%$ SST and the $10 \%$ SBES all predict a similar profile, whereas for the $30 \%$ and the $40 \%$ cases, the swirl increases significantly. This behavior is mainly caused by the large range in the strut's incidence. Overall, the SST and SBES show a similar result in terms of the swirl at the three first evaluation surfaces $\left(\mathrm{FT}, \mathrm{OGV}_{\text {in }}\right.$, and $\left.\mathrm{OGV}_{\text {out }}\right)$, whereas at the NRT evaluation surface, large deviations are observed due to higher degree of momentum transfer between different turbulent structures such as OGV wakes and end-wall boundary layers. Taking previous discussions into consideration, the SBES was able to predict the measured profile of the total pressure for the $10 \%$ case, compared to minor deviations for the SST model.

For the present study, the whole bleed system was included, giving valuable information on the effects from the sparse manifold outlets and the introduction of the bleed pipe struts. Figure 12 shows
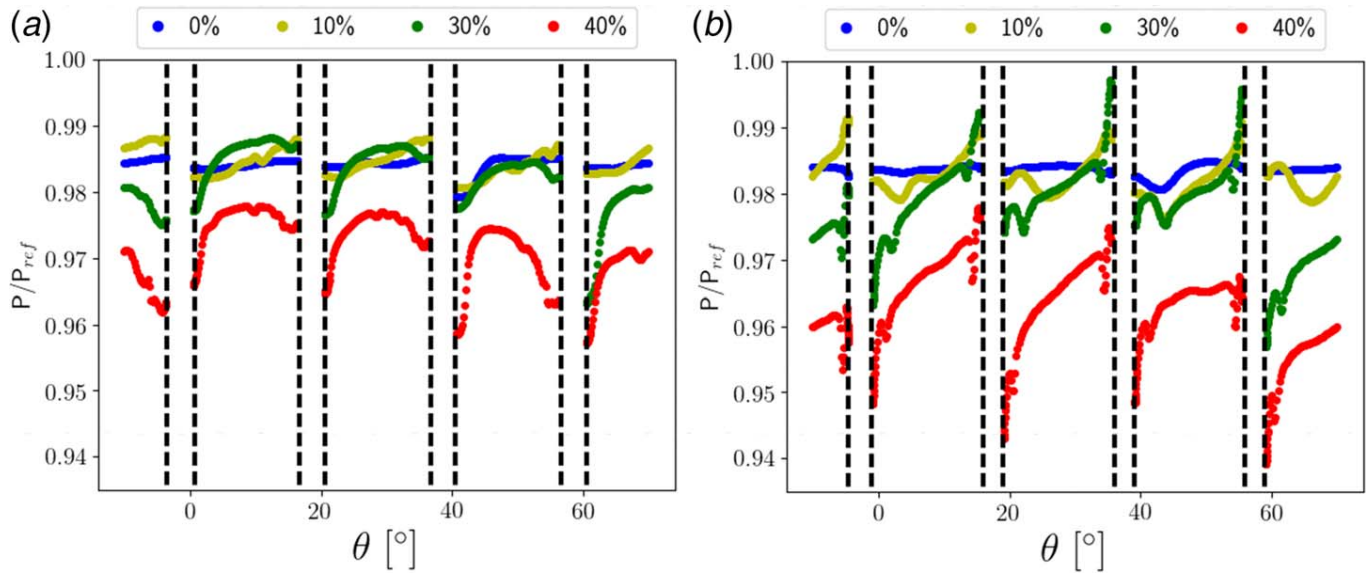

Fig. 12 Normalized pressure at the bleed end-walls. Location marked up and down in Fig. 2. (a) Upstream bleed wall and $(b)$ downstream bleed wall. 

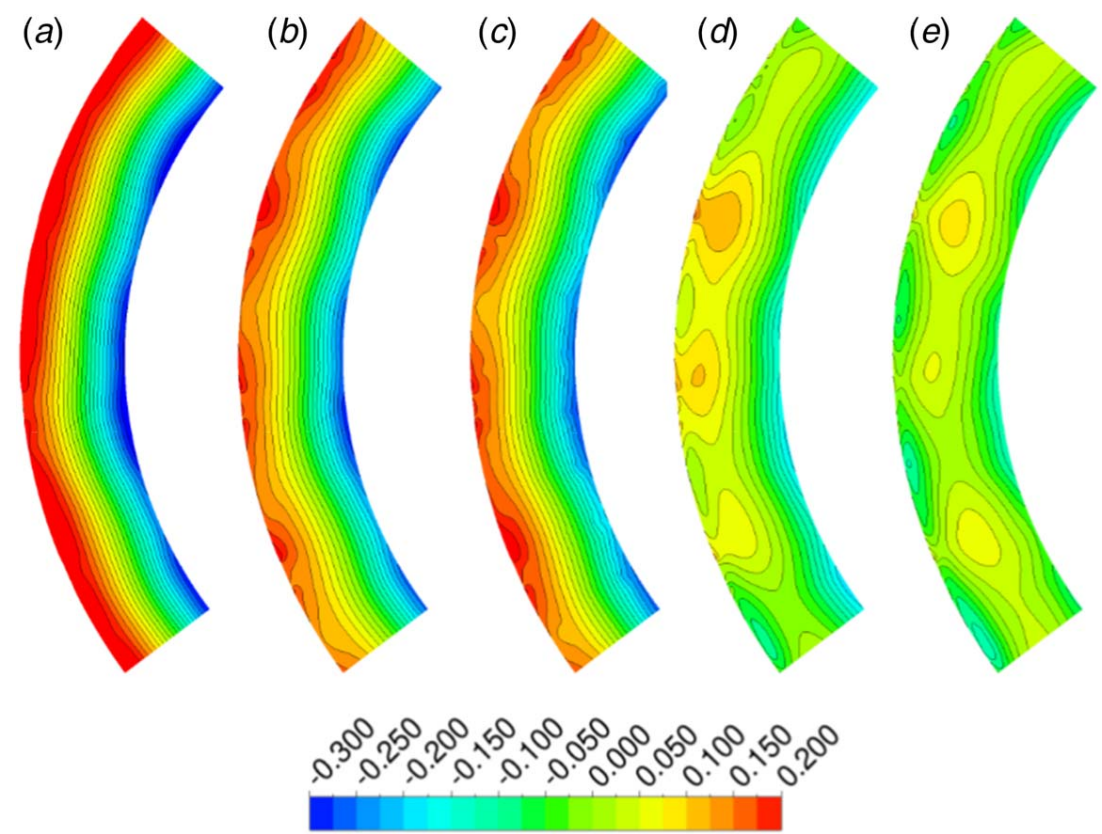

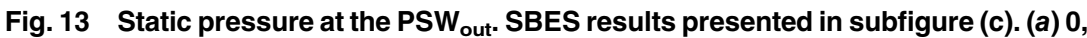
(b) $10,(c) 10,(d) 30$, and (e) 40

the wall pressure inside the bleed pipe as a function of $\theta$, at the upstream and downstream walls (Figs. 2 and 6). In Fig. 12, the bleed pipe struts are represented with vertical dashed lines. The center of the manifold outlet and the two ICD struts are located at $\theta=0 \mathrm{deg}, 20 \mathrm{deg}$, $60 \mathrm{deg}$, respectively. This means that if the manifold outlet would be continuous, instead of the sparse outlet found in a real engine, similar behavior would be observed for $20 \mathrm{deg}$ and $60 \mathrm{deg}$ on one hand and for $0 \mathrm{deg}$ and $40 \mathrm{deg}$ on the other (due to upstream effects from the ICD struts). Because of the discontinuous manifold outlet, the flow will behave differently as a function of the tangential location. The section between the first and last bleed pipe struts $(\theta<0 \mathrm{deg}$ and $\theta>60 \mathrm{deg})$ is the only section where the flow will enter the manifold outlet directly. This is observed in Fig. 12 in terms of the lowest normalized pressure. Furthermore, the potential field from the ICD struts is observed in the figures, even though the OGVs were designed to minimize the upstream potential field. The effects due to the increased bleed are observed in terms of lower static pressure in the bleed pipe, caused by the increase in bleed mass-flow.

The static pressure distortion in the main flow-path, caused by the bleed pipe struts and the sparse bleed manifold outlet, are presented in Fig. 13. All operating conditions show similar behavior, where the potential fields of the four bleed pipe struts are visible near the casing and the potential field of the two ICD struts are visible near the hub (regions of higher static pressure). Furthermore, a difference is observed between the bleed pipe struts, caused by the
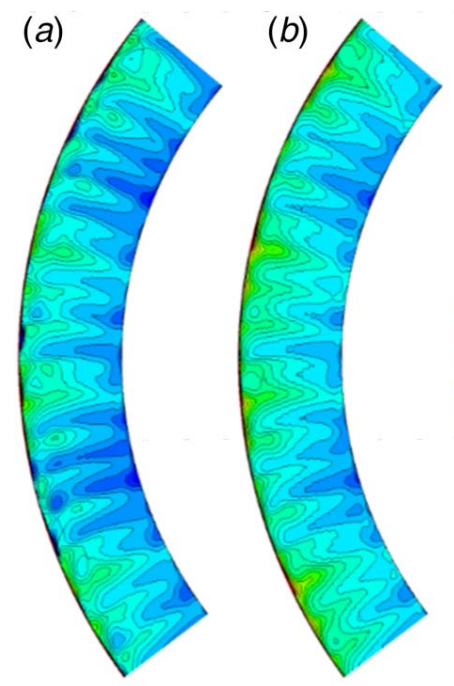

(c)

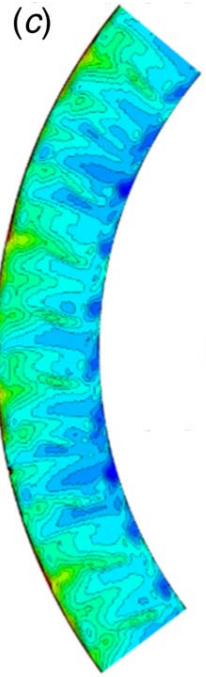

(d)
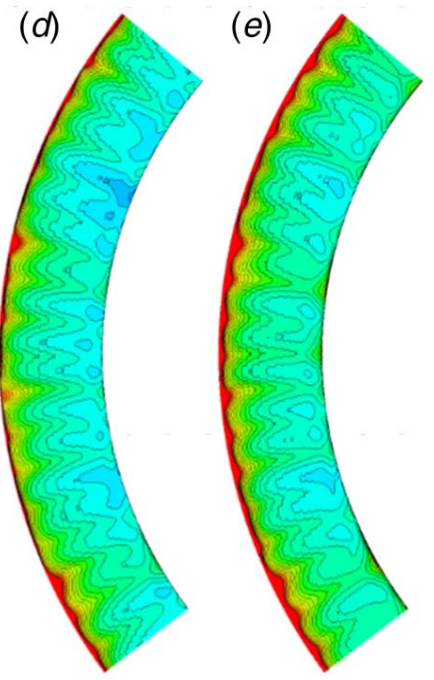

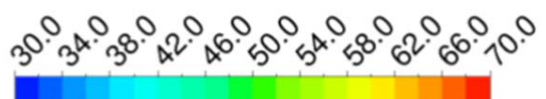

Fig. 14 Swirl at the $O G V_{\text {in }}$ evaluation surface (deg). SBES results presented in subfigure (c). (a) 0 , (b) 10, (c) 10, (d) 30 , and (e) 40 

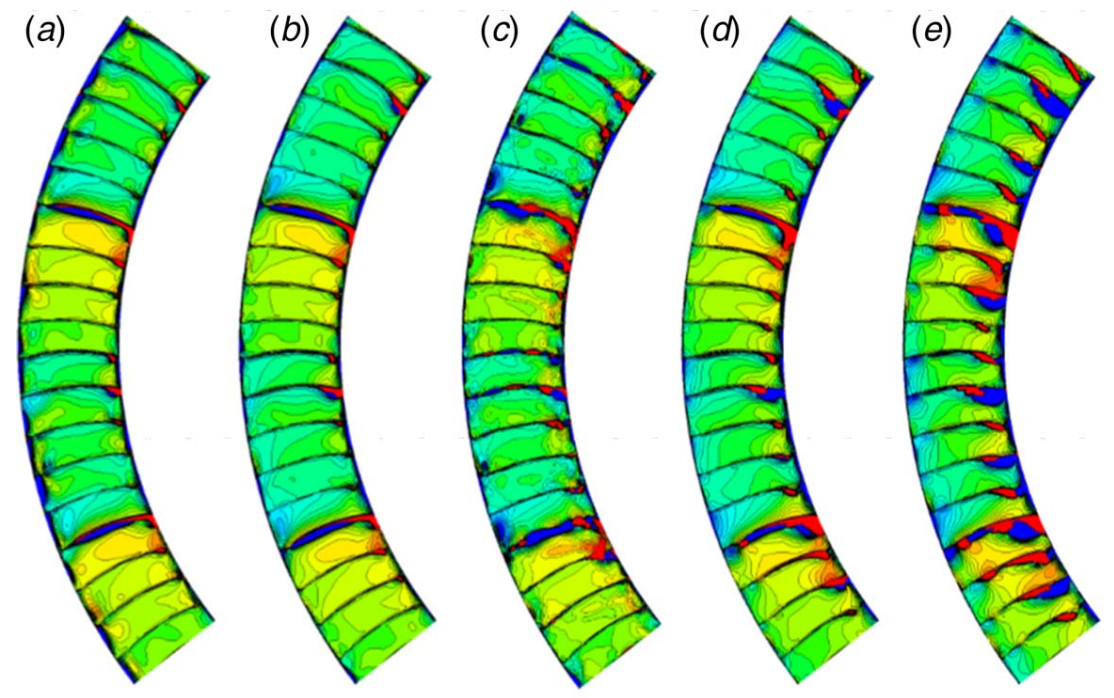

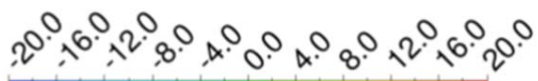

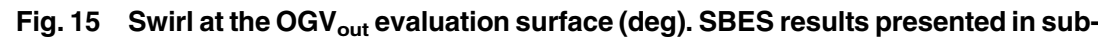
figure (c). (a) 0, (b) 10, (c) 10, (d) 30, and (e) 40
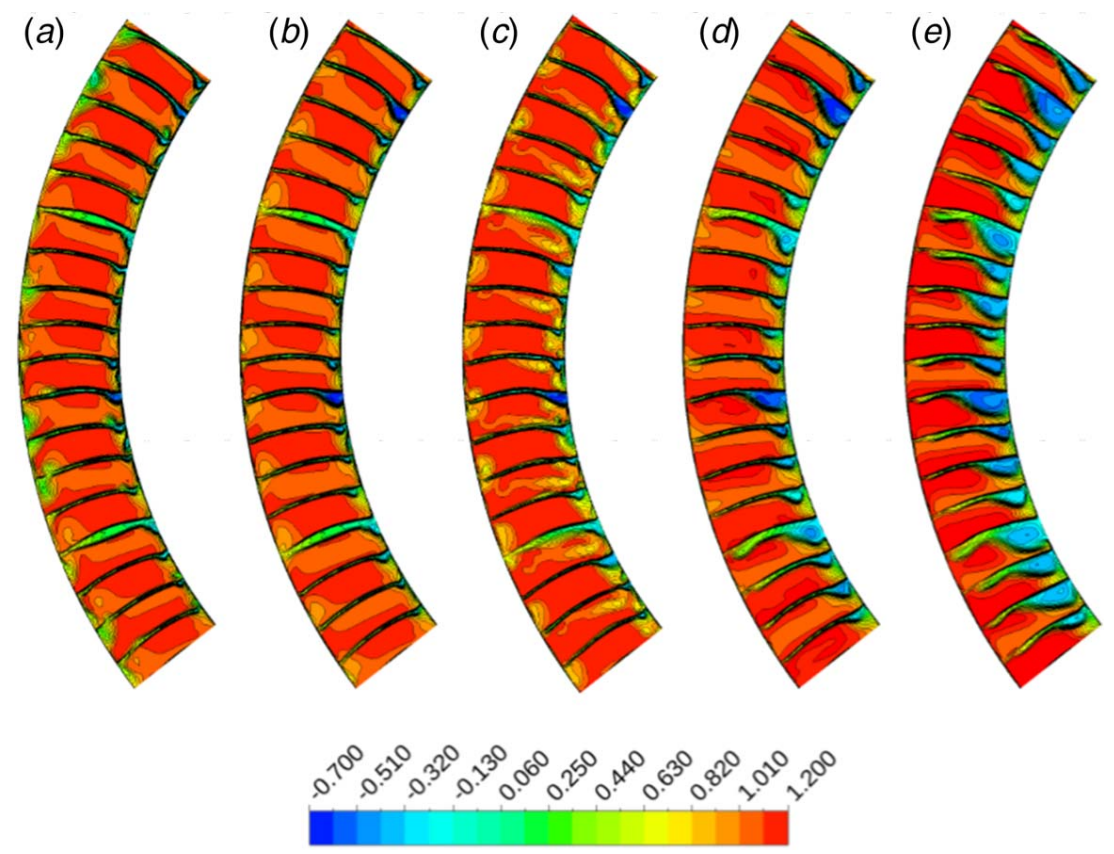

Fig. 16 Total pressure coefficient $\left(C_{P}^{C}\right)$ at the $O G V_{\text {out }}$ evaluation surface. SBES results presented in subfigure (c). (a) $0,(b) 10,(c) 10$, (d) 30 , and (e) 40

single manifold outlet. Even though the manifold outlet is located in the upper part of Fig. 13, due to the tangential momentum and periodic interface, the outlet is "seen" in the lower part. Furthermore, the static pressure field becomes significantly more uniform with increased bleed. This is caused by the redistribution of axial momentum due to the extraction of mass-flow through the bleed pipe.

Figure 14 shows the contours of the swirl at the $\mathrm{OGV}_{\text {in }}$ evaluation surface for all simulations (SST: $0 \%, 10 \%, 30 \%, 40 \%$, and SBES $10 \%)$. As observed in the averaged profiles, presented in Fig $11(b)$, the swirl increases with increased amount of bleed as the axial velocity component is decreased. The effects from the downstream struts are visible in terms of low swirl, where relatively small evidence are of the OGV's potential field (noticed at the casing in terms of 18 wakes for the $40 \%$ operating condition). As expected, the SBES model shows a higher level of details and smaller structures of secondary flow features compared to the SST results.

One important design parameter of the OGV is to deliver as uniform and axial flow as possible to the ICD. Therefore, the swirl at the $\mathrm{OGV}_{\text {out }}$ evaluation surface should be relatively low. Figure 15 shows the contours of the swirl at the $\mathrm{OGV}_{\text {out }}$ location. In the figure, the strut's locations are visible as low-swirl regions, 

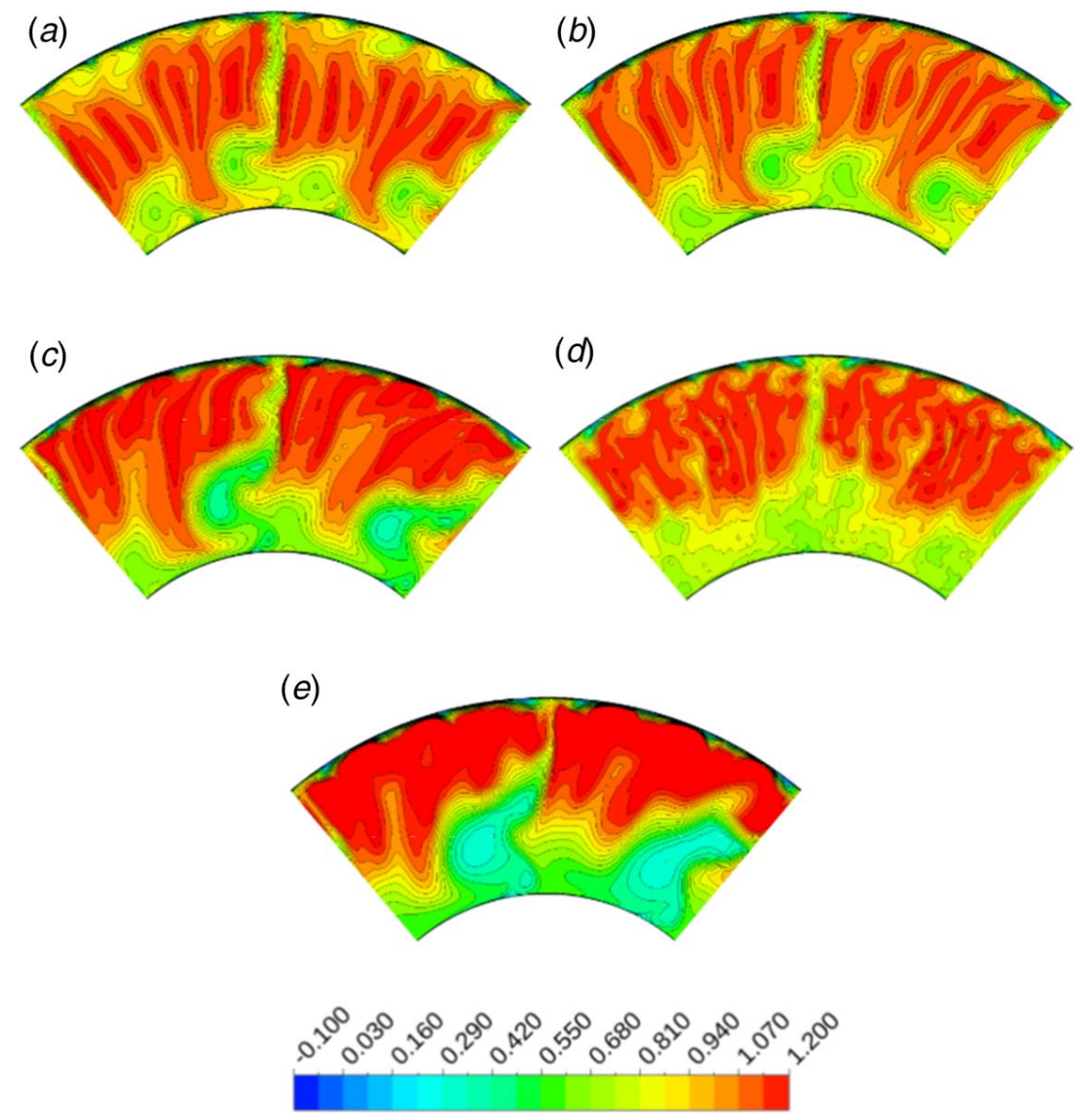

Fig. 17 Total pressure coefficient $\left(C_{\mathrm{P}}^{C}\right)$ at the NRT evaluation surface. SBES results presented in subfigure (d). (a) 0 , (b) 10, (c) 10, (d) 30 , and (e) 40

especially when considering the $0 \%$ and $10 \%$ cases. For the higher bleed fractions, there are strong passage vortices and secondary flows in the near hub region. Comparing the SBES to the SST results, the former shows evidence of much smaller structures and details in the flow. Additionally, stronger effects are visible from the sparse manifold outlet, where difference in swirl can be seen upstream of the two struts.
To further analyze the behavior at the $\mathrm{OGV}_{\text {out }}$ evaluation surface, the contours of the total pressure coefficient (Eq. (4)) are shown in Fig. 16. The flow is separated on the suction surface of the OGVs, where the separation is most severe upstream of the struts and increases in magnitude with increased bleed. As discussed earlier, the swirl and the radial velocity increase with increased bleed, causing flow to separate. As before, smaller structures are noticed

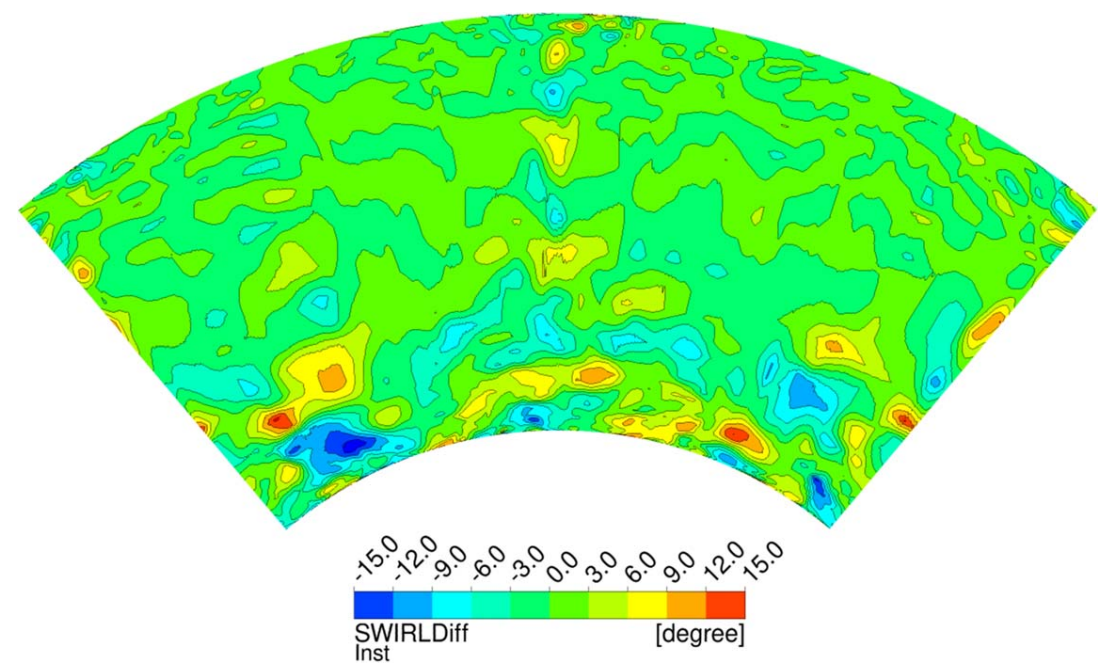

Fig. 18 Difference between time-averaged and instantaneous swirl at the NRT evaluation surface for the $10 \%$ operating condition using the SBES turbulence model (deg) 
for the SBES results, especially when considering the effects from the PSW wakes. Additionally, the effects from the closed manifold outlet can be seen for the $0 \%$ operating condition, where the casing boundary layer and PSW's vortices are observed near the casing and not extracted through the bleed pipe.

The ICD performance can be judged, to some extent, from the quality of the flow delivered to the downstream HPC. Figure 17 presents the CFD contours of the total pressure coefficient at the NRT evaluation surface. The strut's wakes are easily visible, one in the center of the figure and another on the periodic boundary. For the SST results, $0 \%$ and $10 \%$, the passage vortices and wakes are easily identified as they have not mixed to the surrounding flow. For the higher bleed fractions, the vortices have mixed to a greater extent, resulting in a large low total pressure region. Considering the $10 \%$ SBES results, the mixing in the lower half of the annulus is significantly more, resulting in low total pressure region covering the whole tangential sector (where there is no high total pressure region close to the hub). Referring to Fig. 8(b), there was a better agreement in the near hub between the SBES model and the measured values, compared to the SST model. The same behavior was observed when simulating $40 \%$ bleed fraction on a similar configuration, where the mixing in the ICD was important to capture the correct flow physics [10].

The instantaneous effect at the NRT evaluation surface, from the transient simulation, is presented in terms of the difference between the time-averaged and the instantaneous swirl in Fig. 18.

$$
\text { Swirl }_{\text {diff }}=\text { Swirl }_{\text {time-averaged }}-\operatorname{Swirl}_{\text {instantaneous }}
$$

There are significant variations in swirl angles at the ICD exit, which will impact the design of the HPC inlet guide vanes (IGVs). The transient behavior gives the possibility to understand the extremes in terms of operating conditions, resulting in better designed IGVs, producing more uniform flow into the HPC. Additionally, the figure shows how the mixing of the flow is significantly stronger near the hub, compared to the mixing in the upper half, which is the same behavior as seen in Fig. 17. This highly turbulent flow structure energize the flow near the hub, which is the most critical for separating in an aggressive ICD, increasing the stability of the boundary layer making it less prone to separation.

\section{Conclusion}

Series of simulations were performed on a geometry of an experimental rig, which represents an ICD from an aircraft engine. The aim was to study the effects on the ICD performance when removing $0 \%, 10 \%, 30 \%$, and $40 \%$ of the inlet mass-flow through a bleed pipe located upstream of the ICD (rotor off-take). The commercial CFD solver ANSYS CFX was used for the simulations, where all operating conditions where simulated using the $k-\omega$ SST turbulence model. Additionally, a hybrid RANS/LES simulation, using the SBES turbulence model, was performed for the $10 \%$ operation condition.

An initial step is taken to validate the CFD results with measurements obtained in the experimental rig. Overall, there is a good agreement between the measurements and the CFD, especially when considering how the flow is affected by different operating conditions. The SBES results are capable of providing improved predictions for the total pressure profile, downstream of the ICD due to better mixing of the OGV wakes. Even though the SBES improves the results, it must be kept in mind that the computational cost is several orders of magnitude greater [10]. However, the SBES results represent the realistic flow field to some extent, whereas the RANS results will never exist in reality.

When comparing radial profiles of the axial and tangential velocities, it is observed how the increased amount of bleed causes an increase in the tangential velocity (relatively) as the axial flow is extracted through the bleed pipe. This has drastic effects on the ICD performance, where the OGV blades are not capable of delivering as uniform and low-swirl flow into the ICD for high bleed operations. As a result, the downstream HPC would have to be capable of receiving flow with larger deviations in swirl and total pressure. Additionally, by including the full bleed system, significant effects are observed for the pressure in the bleed pipe. The full bleed system also causes circumferential distortions of the static pressure in the main flow-path upstream of the bleed.

Furthermore, the flow does not separate at the hub of the ICD for any operating condition (not in CFD nor experiments), which is the most critical location for an aggressive ICD. This means that, even though the current ICD geometry is a state-of-the-art design, it could be pushed further and a shorter and lighter engine could be achievable. However, the OGV design would need improvements to be capable of delivering high-quality flow, with minimum separation and low swirl, into the ICD for high bleed fractions.

Another solution could be to use a stator off-take instead of the rotor off-take used in this configuration. That would place the bleed pipe downstream of the OGV. As the OGVs are designed to deliver a low-swirl flow, the effects on the downstream swirl would be minimum, simplifying the mechanism discussed. There are, however, other impact factors that should be taken into consideration, such as particle extraction.

\section{Acknowledgment}

This research work was funded by the Swedish National Aviation Engineering Research Program, NFFP with financial support from VINNOVA and the Swedish Defense Material Administration (FMV). The authors would like to thank Ulf Johansson and Steffen Hammer for their support with the experimental data processing. The authors would also like to acknowledge GKN Aerospace Engine Systems (GKNAES) for permission to publish their work. The CFD simulations were performed on resources at Chalmers Centre for Computational Science and Engineering (C3SE) and High Performance Computing Center North (HPC2N) provided by the Swedish National Infrastructure for Computing (SNIC).

\section{Conflict of Interest}

There are no conflicts of interest.

\section{Data Availability Statement}

The authors attest that all data for this study are included in the paper.

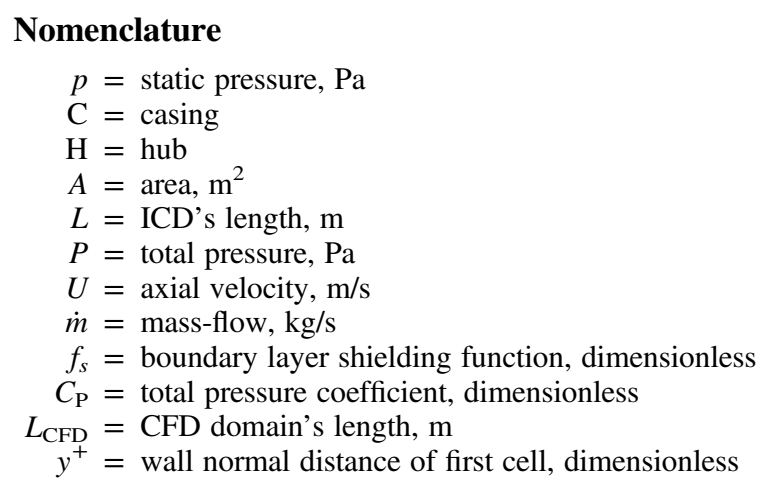

\section{Greek Symbols}

$\theta=$ cylindrical coordinate: tangential direction, $\mathrm{deg}$

$\nu=$ kinematic viscosity, $\mathrm{m}^{2} / \mathrm{s}$

$\nu_{t}=$ eddy-viscosity, turbulence model variable, $\mathrm{m}^{2} / \mathrm{s}$ 


\section{Subscripts}

bleed $=$ bleed pipe

in $=$ inlet

norm $=$ normalized value

out $=$ outlet

sector $=$ annulus divided into radial sectors

\section{Superscripts}

$$
\begin{aligned}
& c=\text { contours } \\
& r=\text { radial profiles }
\end{aligned}
$$

\section{References}

[1] Britchford, K. M., Carrotte, J. F., Stevens, S. J., and McGuirk, J. J., 1994, “The Development of the Mean Flow and Turbulence Structure in an Annular S-Shaped Duct," International Gas Turbine and Aeroengine Congress and Exposition, The Hague, The Netherlands, June 13-16, Vol. 1, No. 1, p. V001T01A144.

[2] Britchford, K., Manners, A. P., McGuirk, J., and Stevens, S., 1994, "Measurement and Prediction of Low in Annular S-Shaped Ducts," Exp. Therm. Fluid Sci., 9(2), pp. 197-205.

[3] Bailey, D. W., Britchford, K. M., Carrotte, J. F., and Stevens, S. J., 1997, "Performance Assessment of an Annular S-Shaped Duct," ASME J. Turbomach., 119(1), pp. 149-156.

[4] Bailey, D. W., and Carrotte, J. F., 1996, "The Influence of Inlet Swirl on the Flow Within an Annular S-Shaped Duct,” p. 60, ASME Paper 96-GT-60.
[5] Walker, A. D., Barker, A., Carrotte, J. F., Bolger, J., and Green, M., 2013, "Integrated Outlet Guide Vane Design for an Aggressive S-Shaped Compressor Transition Duct," ASME J. Turbomach., 135(1), p. 011035.

[6] Walker, A. D., Barker, A. G., and Carrotte, J. F., 2011, "Numerical Design and Experimental Evaluation of an Aggressive S-Shaped Compressor Transition Duct With Bleed," ASME 2011 Turbo Expo: Turbine Technical Conference and Exposition, Vancouver, British Columbia, Canada, June 6-10, American Society of Mechanical Engineers, pp. 151-161.

[7] Grimshaw, S., Pullan, G., and Walker, T., 2015, "Bleed-Induced Distortion in Axial Compressors," ASME J. Turbomach., 137(10), p. 101009.

[8] Grimshaw, S., Pullan, G., and Hynes, T., 2016, "Modeling Nonuniform Bleed in Axial Compressors," ASME J. Turbomach., 138(9), p. 091010.

[9] Siggeirsson, E. M. V., Andersson, N., and Wallin, F., 2018, "Numerical and Experimental Study on Bleed Impact on Intermediatecompressor Duct Performance," ASME Turbo Expo 2018: Turbomachinery Technical Conference and Exposition, Oslo, Norway, June 11-15.

[10] Siggeirsson, E. M. V., Andersson, N., and Olander, M. B., 2019, "Integrated Compressor Duct With Bleed: Experimental Validation of a Hybrid RANS/ LES Approach," ISABE 2019, Canberra, Australia, Sept. 22-27.

[11] Spalart, P. R., 2000, "Strategies for Turbulence Modelling and Simulations," Int. J. Heat Fluid Flow, 21(3), pp. 252-264.

[12] Menter, F., 2018, Stress-Blended Eddy Simulation (SBES) - A New Paradigm in Hybrid RANS-LES Modeling, Y. Hoarau, S. Peng, D. Schwamborn, and A. Revell, eds., Springer International Publishing, Switzerland, pp. 27-37.

[13] Nicoud, F., and Ducros, F., 1999, "Subgrid-Scale Stress Modelling Based on the Square of the Velocity Gradient Tensor," Flow Turbulence Combust., 62(3), pp. $183-200$.

[14] Menter, F., 2015, "Best Practice: Scale-Resolving Simulations in ANSYS CFD," Technical Report, 2, ANSYS Germany GmbH, November.

[15] Spalart, P. R., 2001, "Young-Person's Guide to Detached-Eddy Simulation Grid," Technical Report, NASA/CR-2001-211032, NASA Langley Technical Report Server, Moffett Field, CA 